\title{
A needs assessment for mobile technology use in medical education
}

\author{
Shahrzad Vafa' ${ }^{1}$, Diane E. Chico² \\ ${ }^{1}$ Baylor College of Medicine, Houston, TX, USA \\ ${ }^{2}$ College of Medicine, Texas A\&M University Health Science Center, USA
}

Correspondence: Shahrzad Vafa, BCM: Education Resource Center, 2nd Floor, One Baylor Plaza, Houston, Texas 77030, USA.

Email: svafa@bcm.edu

\begin{abstract}
Objectives: This study investigated how medical students perceived mobile technology as a component of their learning experience and identified barriers to the use of mobile technology in education.

Methods: An anonymous survey developed by EDUCAUSE was distributed to 1000 first year medical students (M1s) at two separate medical schools during three consecutive academic years, 2010 to 2013 . The 25-item questionnaire assessed student use of mobile devices, student interest in mobile technologies as they apply to education, and technology issues related to implementing mobile application in education.

Results: The majority of participating M1s $(n=520)$ indicated that they own a smartphone or a similar mobile device. More than half of M1s reported using their devices for education, primarily to download educational course
\end{abstract}

materials, listen to podcasts/lectures, and access medical resource applications. Two student-identified technology issues concerning the use of mobile technology in education were ensuring better implementation of technology and faster data transmission $(60 \%)$. Review of qualitative data from written responses to open-ended questions highlighted three common themes: (1) the current use of mobile technology in the clinics and other institutions, (2) common technology ownership and comfort of use, and (3) efficiency and accessibility to learning materials.

Conclusions: While the needs assessment revealed student acceptance of mobile technology in education, student responses highlighted the need for a supportive academic and technological infrastructure.

Keywords: Mobile learning, undergraduate medical education, mobile technology

\section{Introduction}

The use of mobile computing devices such as smartphones is rapidly increasing in the population. According to Gartner, Inc., a technology research and advisory firm, by 2013 mobile phones will overtake personal computers (PCs) as the most common Web access device worldwide, and by 2015 over $80 \%$ of the cellular phones sold in markets will be smartphones. ${ }^{1}$ A smartphone is commonly defined as a mobile phone that offers computer application platforms and connectivity in addition to functionality as a cellular phone. In a recent 2013 study generated by Ball State University's annual survey, $73 \%$ of the student population reported using a smartphone for daily activities as compared to the $27 \%$ of students reported in 2009. ${ }^{2}$ According to Michael Hanley, Associate Professor at Ball State University, "The complete reversal of mobile device usage reflects the explosive growth of Internet-accessible, computer-like smartphones away from text and talk feature phones." ${ }^{2}$ As mobile handheld devices become more widespread in use, the concept of mobile learning is being introduced as a strategy in learner-centered education.

The move toward more learner-centered education lends itself to using instructional strategies that engage students in identifying and comprehending key concepts, receiving feedback in the course of the student's learning process, and applying concepts to relevant situations. An ever-growing number of healthcare professionals view mobile devices as a way to increase job efficiency and assist in improving the quality of healthcare delivery. Hence, the "Anytime, Anywhere" services offered by current mobile device technology show promise as an instructional tool 
that can lead to efficient and improved quality of content delivery.

Mobile learning, or "m-learning," is broadly defined as the delivery of learning content using mobile technology that is accessed at a student's convenience from any location. ${ }^{3}$ Several studies have indicated that mobile, wireless device technology supports teaching and learning. ${ }^{4-6}$ M-learning has the potential for interactive instruction as a self-study education resource or during live formal lectures, laboratory sessions, and self- assessments similar to the automated response system. ${ }^{7}$ Moreover, an increasing number of physicians, residents, and medical students currently use mobile devices such as smartphones, iPads, and tablets for education and use in clinical environments. ${ }^{8-12}$ Current literature reviews have shown that research on mobile technology in medical education, and in health professional education in general, primarily focus on efficacy of mobile devices as an educational tool and resource, infrastructure to support m-learning, benefits, challenges, and appropriate use. ${ }^{13-17}$ The principles central to the use of mobile technology in medical education draw from current m-learning and socio-cultural theories as well as conceptual frameworks from technology-enhanced learning and mobile human-computer interaction. ${ }^{18}$ Pedagogical studies suggest that successful development and implementation of mobile educational technology involve the common themes of: (1) device portability, (2) learner mobility and situation, (3) interactivity and collaboration, and (4) relevance of technology in the educational environment.

Implementing mobile technology for the sake of technology alone will not lead to maximal use and acceptance by students, staff, and faculty. Knowledge of the learner's needs, teaching needs, and learning context are required to support positive utility of mobile learning. In order to take advantage of the growth of mobile devices and to provide timely technology resources for medical students, we performed a formal analysis to determine the overall state of mobile technology use by first year medical students (M1s) at our institutions.

The aims of the study were to investigate student perceptions of information technology, particularly mobile technology, as a component of their learning experience in medical education and student identification of barriers to the implementation of mobile technology. To gather the information, we distributed a short survey, Mobile Educational Technology in Medical Education, to first year medical students at two different medical school institutions: the Baylor College of Medicine in Houston, Texas and the Texas A\&M Health Science Center College of Medicine in Bryan Texas during three consecutive academic years, 2010 to 2013. We wanted to learn more about student access to mobile computing equipment and accessories and to provide evaluation data for existing mobile technology use. Based on the results of the survey, we were able to address the following areas: (1) ownership of mobile phone and applications, (2) use of mobile technology for educational activities, (3) primary use of mobile devices, and (4) barriers to using mobile technology in education.

The present study was conducted as a "needs assessment" to examine the emerging trend of mobile technology use by medical students as an educational tool in two similar institutions. The results of the needs assessment by students provided potential areas for future development in educational use such as reliable information of medical students' behaviors, preference, and use of technology. The results can provide insight to medical institutions interested in implementing technology environments that utilize mobile learning (or m-learning).

\section{Methods}

All first year students at the Baylor College of Medicine (BCM) and the Texas A\&M Health Science Center College of Medicine (TAMHSC COM) were invited to participate in the study. Before conducting the study, ethical approval for the study was given by the Institutional Review Board (IRB) committees of both Baylor College of Medicine and the Texas A\&M University System. The students were informed of the study at orientation lectures in Histology, during the orientation of incoming students, on the course learning management system, and by emailed invitations to all students. All participants were provided with written information about the study and consent for participation before the study started. They were informed that this study is completely voluntary, and they can withdraw from the study or stop participating at any time.

\section{Study design}

The study was designed as a descriptive analysis to assess emerging patterns of mobile technology use by medical students across three academic years, 2010-2011, 20112012, and 2012-2013. The questionnaire used for this study was adopted from sections of an extensive survey that was developed by EDUCAUSE, a nonprofit association whose mission is to advance higher education through the use of information technology.

In 2010, EDUCAUSE publications used an extensive survey to provide colleges and university administrators with reliable information on 'undergraduates' behaviors, preference, and overall satisfaction with technology." 19 The 2010 survey consisted of more than 70 questions and a final open-ended comment section. Each question was individually evaluated and tested for reliability and functionality by EDUCAUSE principal researchers. ${ }^{19}$ The adopted short electronic survey used in this study was distributed to approximately 1000 first year medical students in two separate medical school institutions during the months of August to October of academic years 2010-2011, 2011-2012, and 2012-2013. The 25-item survey questionnaire covered three main topics: student use of mobile devices, student 
interest in mobile technologies as they apply to education, and technology issues related to implementing mobile application in education.

\section{Data analysis and collection}

A web-based quantitative survey was used to gather data. The design and analysis of the survey was provided by the online survey tool, Survey Monkey (Palo Alto, CA). The survey included several open-ended sections that were further analyzed by Microsoft Excel software to illustrate discussions of the quantitative data. This study also reported a comparison of longitudinal data from the three consecutive years. This data was collected to learn more about the emerging patterns and trends in mobile education as reported by students. Each author independently identified themes to the responses, and the most common threads were reported.

\section{Results}

More than one thousand students were enrolled at Baylor College of Medicine (545 students) and the College of Medicine at Texas A\&M Health Science Center (550 students) over three academic years (2010-11, 2011-12, and 2012-13). A total of approximately 520 students voluntarily participated in the study during these years. Survey data provided information on barriers, technology issues, and student interest in mobile technologies as they apply to education.

\section{Student ownership of mobile devices}

Data analysis indicated that the majority of first year medical students owned a smartphone or a similar mobile device (Figure 1). The data also showed an increase in the ownership from 2010-2011, where approximately 55\% of students had a smartphone or mobile device. In the 20122013 study, $91 \%$ of students owned a smartphone or similar device.

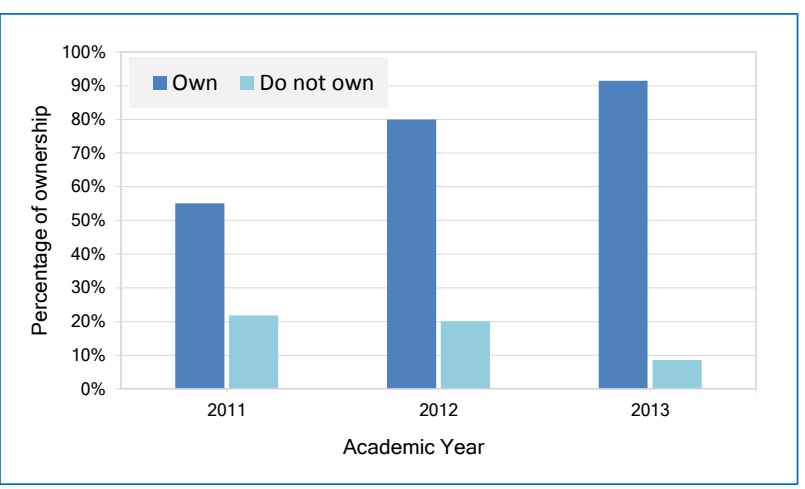

Figure 1. Student Ownership of Mobile Devices. Mobile devices were identified as smartphones such as iPhone, Android, and handheld tablet devices such as iPad. Percentages (\%) of those responded from Baylor College of Medicine ( $n=340$ respondents) and Texas A\&M Health Science Center College of Medicine $(n=180$ respondents) were merged $(n=520)$
Preference for use of information technology in courses Overall, participants indicated their preference for incorporating informational technology in education. In the 20102011 study, approximately $60 \%$ of students preferred the use of technology extensively in the courses. Cohorts of the subsequent two academic years (2011-2012 and 2012-2013) perceived that only moderate use of technology is necessary in education (Figure 2).

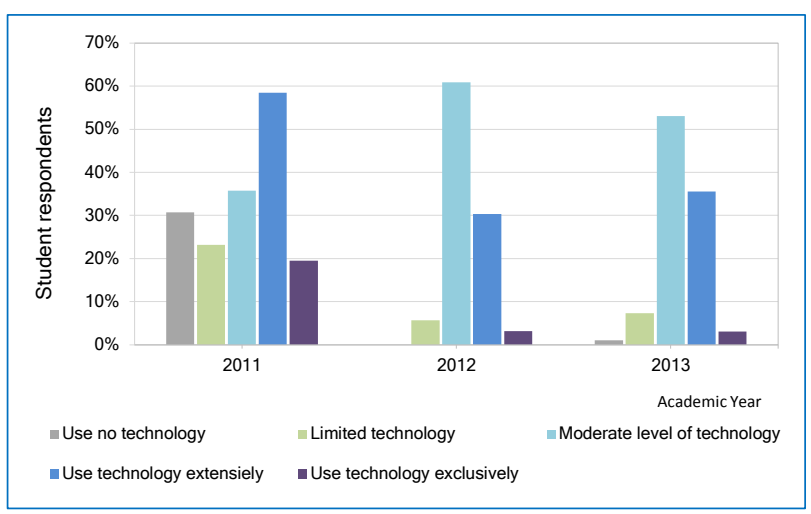

Figure 2. Student participants' reported preference for use of information technology in courses. Percentages (\%) of those responded from Baylor College of Medicine ( $n=340$ respondents) and Texas A\&M Health Science Center College of Medicine $(n=180$ respondents) were merged $(n=520)$

\section{Student use of mobile device for education}

Students' primary uses of mobile devices were assessed by self-reporting. The three main uses of a mobile device by students were Recreation (82.5\%), Communication (81.7\%), and Education (62.7\%) (Figure 3). More than half of the students (above 60\%) reported that they have used their devices for education, primarily to download education course materials (50\%) and listening to podcasts and/or recorded lectures (17\%). The use of mobile devices for education has not changed over the three academic years.

The majority of students (approximately 70\%) reported that they were not currently using their mobile devices to access medical resource applications. This number has not changed over the last three academic years, likely due to curricular changes that did not include increased implementation of mobile technology as educational tools. However, when asked if they would use their devices for reviewing instructional materials, over $75 \%$ of student respondents reported that they would use their mobile devices as a study device. Over $75 \%$ of student respondents indicated interest in learning more about available application use for educational purposes. The three main applications that the majority of students indicated should be provided by the institution were flash cards such as Gray's or Netter's anatomy (90\%), Mosby's pocket dictionary (60\%), and UpToDate (50\%).

\section{Barriers to using mobile technology in education}

Students identified certain technology issues concerning the use of mobile technology in education that should be 
addressed in order to make smaller mobile devices popular for educational use. The majority of students indicated (over 60\%) that they would prefer to have larger displays, which provide for better readability and viewing of learning materials. In addition, they would favor better deployment of technology and faster data transmission (60\%). The other factors that students identified as barriers for successful implementation of mobile technology in education were connectivity $(70 \%)$, price of application $(63 \%)$, and internet speed $(60 \%)$.

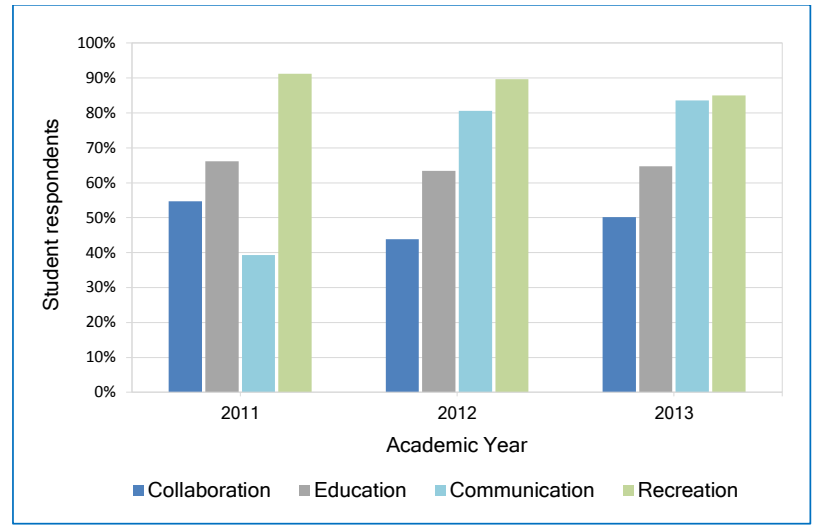

Figure 3. Primary uses of mobile devices by students. Percentages (\%) of those responded from Baylor College of Medicine ( $n=340$ respondents) and Texas A\&M Health Science Center College of Medicine ( $n=180$ respondents) were merged $(n=520)$

Open-ended comments suggested that the majority of students perceived the use of mobile technology in medical education as a feasible application. Comments highlighted three common themes: (1) the current use of mobile technology in the clinics and other institutions, (2) common technology ownership and comfort of use, and (3) efficiency and accessibility to learning materials.

\footnotetext{
"It's absolutely feasible. In fact, I would go so far as to say that the integration of mobile technology to not only medical education, but medical practice, is inevitable. As such, it should be actively and enthusiastically pursued if BCM wants to remain a competitive institution." (2010-2011, student \#9)

"I think not only is it feasible but an absolute must. The future is driven by computing and only by using the technologies as they come out will we be prepared for that future." (2011-2012, student \#3)

"I primarily use mobile technology in regards to education as a supplement to what I am currently learning in lecture or through the textbook-mobile technology can provide certain interactive features that cannot be accessed through learning strictly in the classroom setting, thus I think investing in a mobile device that can download educational tools can be very helpful in the learning process." (2012-2013, student \#28)
}

However, a small percentage of students perceived that mobile technology is best used "not in the classroom [but] in the hospital setting and outside of class use." Others indicated that mobile technology "should not be used as the sole source but as a helpful resource" for education. Fur- thermore, implementation of mobile technology in education may not be cost effective, particularly for students due to expense of owning a smartphone, lack of confidence with the schools' instructional technology infrastructure, and difficulty in addressing the needs of everyone.

"I think it's a very feasible application. The problem is that this all costs a lot, and, if we are to be expected to have a mobile technology, it should be included in the booklist so that we can anticipate our expenses." (2012-2013, student \#14)

"No. [N]ot everyone has a mobile devise with this capability; this pathway may lead to the possibility that at some point this will become mandatory. These are personalized study techniques that each student may or may not like. [T] hey should be able to decide for themselves and not be pressured to use this technology if they are not comfortable with it. Also it takes away from the hands on teaching available from professors; which is usually superior to these types of technology education materials." (2010-2011, student \#37)

"Significant training and added staff would be necessary before this idea could even be brought up in a real conversation." (2010-2011, student \#20)

\section{Discussion}

Student responses indicated that mobile devices are potential avenues for reviewing instructional materials, an invaluable resource for immediate feedback, and other educational purposes. These past three years have seen an increase in literature reporting successful utility of mobile technology in higher education. ${ }^{11,12,17,20}$ However, the use of mobile technology in education is a relatively new phenomenon. Therefore, there is a need to do a systematic curriculum planning before implementing the mobile technology initiative. We utilized the six-step approach proposed by Kern et al. to provide a conceptual framework for this new curriculum development. ${ }^{21}$ One of the important steps in the Kern et al. framework is to perform a needs assessment before any implementation.

Moreover, results from this present study reflected prior needs assessment reports with regard to two separate issues: student use of mobile technology and the appropriate track of institutions taking advantage of this technology to enhance the learning process. Mobile application and technology issues should be addressed by each institution in order to successfully incorporate mobile technology in education, particularly with regard to resources in terms of computer technology, institutional technology infrastructure, faculty awareness of efficient application of mobile devices for content delivery, and student accessibility.

Highly portable devices such as tablets and iPads continue to find a niche as instructional tools to enhance the academic experience. But, as Danny Finuf, president of Brown Mackie College emphasized in response to equipping all of the students in Brown Mackie with an iPad, "You won't be successful if the faculty is not on board and don't see the value for them and their students. Administrators 
have to make sure that faculty are integrated into the process, that they understand this is where education is going, and that they have the training and resources to feel properly supported." 22 Nevertheless, students will use mobile technology such as iPads because they provide ondemand accessibility to information regardless of whether faculty will incorporate such technology in their teaching. This study is limited by the personal reporting of voluntary respondents. A possible inherent issue in their responses is bias related to prior experiences with technology and external factors that may influence their academic performance. Several studies suggested positive acceptance of personal digital assistants, iPads, iPods, etc. as useful instructional resources for students. Furthermore, data was only collected from first year students at the start of matriculation of each academic year of the study and from only two institutions. First year students were selected as participants because the authors' have primary teaching responsibilities in the first year undergraduate medical curriculum. Thus, this study represented the perceptions of one population of students and not students throughout all four years. Nevertheless, the technology and mobile devices used by all students were similar.

Davies and colleagues reported one of the first studies describing the learning technology behind the use of mobile learning technologies in undergraduate medical education. ${ }^{8}$ Their conceptual framework suggested that mobile learning in the clinical setting offered contextual learning via "justin-time" experiences and problem-solving scenarios which requires "repeated active application of the knowledge acquired." As Davies and colleagues further discussed in their study, the design of mobile platforms for implementation in medical education should incorporate accessibility to relevant information at different times and different locations, resource cost and infrastructure, and equitable use of devices among students. This fits in with our study on the needs assessment of students for their acceptance of mobile educational technology.

The results of the present study proved useful for both institutions involved. The Information Technology (IT) department of BCM was interested in implementing a pilot for a mobile initiative for the 2013-14 academic calendar. The needs assessment of this study was shared with IT and provided them with insight on the ownership and use of mobile devices as well as the importance of IT infrastructure and support for the success of the implementation. For the Texas A\&M Health Science Center, the study shed slight on students' expectations and preference on the use of technology in classrooms. The needs assessment revealed opportunities for enhancements in instructional technology, accessible content delivery, and computer-based testing.

\section{Conclusion}

The lessons from this study are transferable nationally and internationally to other medical schools that are in the process of developing similar educational initiatives utilizing mobile devices as instructional resources. The data gathered from the present study can be used to: (1) learn more about students' mobile computing equipment and accessories, (2) provide evaluation data for existing mobile technology use, (3) develop needs assessment data for future implementation of mobile technology in education, and (4) inform administrative decisions regarding support for mobile technology use. The strength of this study is that the cohort of student participants at two different institutions, one being private and one public, showed comparable agreement in their needs assessment of mobile technology in education. With increasing use of portable devices by students and faculty, it is logical to expect the next step to incorporate these devices in the learning environment. A comprehensive survey of all medical students in the undergraduate curriculum could reveal changes in student's need assessment for mobile educational technology as they move from the preclinical/pre-clerkship curricula to the clerkship curriculum.

\section{Conflict of Interest}

The authors declare that they have no conflict of interest.

\section{References}

1. Gartner Inc. Gartner identifies the top 10 strategic technology trends for 2013. Gartner Newsroom. 2010 [cited 2 April 2013]; Available from: http://www.gartner.com/newsroom/id/2209615.

2. Ransford M. Majority of college students own smartphones, but dislike those ads. Ball State University News Center. 2013 [cited 2 April 2013]; Available from: http://cms.bsu.edu/news/articles/2013/2/students-embracetheir-smartphones.

3. Caudill J. The growth of m-learning and the growth of mobile computing: parallel developments. The International Review of Research in Open and Distance Learning. 2007 [cited 14 February 2013]; Available from: http:// www.irrodl.org/index.php/irrodl/article/view/348/873.

4. Dearnley C, Haigh, J, Fairhall J. Using mobile technologies for assessment and learning in practice settings: a case study. Nurse Education in Practice. 2008; 8: 197-204.

5. Nowinski WL, Thirunavuukarasuu A, Ananthasubramaniam A, et al. Automatic testing and assessment of neuroanatomy using a digital brain atlas: Method and development of computer- and mobile-based applications. Anatomical Sciences Education. 2009;2:244-252.

6. Trelease RB. Diffusion of innovations: Smartphones and wireless anatomy learning resources. Anatomical Sciences Education. 2008;1:233239.

Peters, K. m-Learning: positioning educators for a mobile, connected future. The International Review of Research in Open and Distance Learning, 2007 [cited 14 February 2013]; Available from: http://www.irrodl.org/index. php/irrodl/article/view/350/894.

8. Davies BS, Rafique J, Vincent TR, Fairclough J, Packer MH, Vincent R, Haq I. Mobile how mobile information resources contribute to learning for undergraduate clinical students -A mixed methods study. BMC Medical Education. 2012;12:1.

9. Mayfield CH, Ohara PT, O'Sullivan PS. Perceptions of a mobile technology on learning strategies in the anatomy laboratory. Anatomical Sciences Education. 2012; 6(2):81-9.

10. Pimmer C, Linxen S, Gröhbiel U, Jha AK, Burg G. Mobile learning in resource-constrained environments: a case study of medical education. Medical Teacher. 2012; e1-e9.

11. Schulman CI, Garcia GD, Wyckoff MM, Duncan RC, Withum KF, Graygo J. Mobile learning module improves knowledge of medical shock for forward surgical team members. Military Medicine. 2012;177(11):13161321 . 
12. Tews M, Brennan K, Begaz T, Treat R. Medical student case presentation performance and perception when using mobile learning technology in the emergency department. Medical Education Online. 2011;16:7327.

13. Chu LF, Erlendson MJ, Sun JS, Alva HL, Clemenson AM. Mobile computing in medical education: opportunities and challenges. Current Opinion in Anesthesiology. 2012;25:699-718.

14. Sandars J. Technology and the delivery of the curriculum of the future: opportunities and challenges. Medical Teacher. 2012;34:534-538.

15. Wallace S, Clark M, White J. 'It's on my iPhone': attitudes to the use of mobile computing devices in medical education, a mixed-methods study. BMJ Open. 2012;24;2(4).

16. Kearney M, Schuck S, Burden K, Aubusson P. Viewing mobile learning from a pedagogical perspective. Research in Learning Technology. 2012 [cited 23 Nov 2013]; Available from: http://www.researchinlearning technology.net/index.php/rlt/article/view/14406.

17. Lea S, Callaghan L. Enhancing health and social care placement learning through mobile technology. Educational Technology and Society. 2011;14 (1): 5-145.
18. Wingkvist A, Ericsson M. A survey of research methods and purposes in mobile learning. International Journal of Mobile and Blended Learning. 2011;3(1):1-17.

19. Smith S, Caruso J. ECAR study of undergraduate students and information technology. EDUCAUSE- ECAR Publications. 2010 [cited 2 May 2013]; Available from: http://www.educause.edu/library/resources/ecar-stud y-undergraduate-students-and-information-technology-2010.

20. Davies JS, Garcia GD, Wyckoff MM, Alsafran S, Grayho J, Withum, KF, et al. Use of mobile learning module improves skills in chest tube insertion. Journal of Surgical Research. 2012;177:21-26.

21. Kern DE, Thomas PA, Howard DM, Bass EB. Curriculum development for medical education: a six-step approach. Johns Hopkins University Press. $1998 ; 4-7$.

22. Fuhrman T. Making the iPad the center of the academic experience. Campus Technology. [cited 14 February 2013]; Available from: http://camp ustechnology.com/articles/2013/02/14/making-the-ipad-the-center-of-theacademic-experience.aspx. 